\title{
ANALISIS SWOT INOVASI LINI BISNIS PT. PINDAD (PERSERO): PELAYANAN KEAMANAN SIBER
}

\author{
Muhammad Haikal Kautsar ${ }^{1}$, Nurina Munasyaroh², Putri Alyani Fadhilah ${ }^{3}$, \\ Ikhsan Yoga Utama ${ }^{4}$, Supandi ${ }^{5}$
}

\begin{abstract}
Abstrak: PT.PINDAD (Persero) adalah perusahaan milik negara yang bergerak di sektor industri pertahanan, saat ini telah melakukan inovasi pada lini bisnisnya. PT.PINDAD (Persero) yang memiliki bisnis utama dalam produksi Alutsista kini menyediakan jasa pelayanan keamanan siber. Penelitian ini bertujuan untuk melakukan analisis strategi PT.PINDAD (Persero) dalam pengembangan produk barunya menggunakan pendekatan SWOT dan QSPM. Penelitian ini menggunakan pendekatan kualitatif dengan cara pengumpulan data melalui wawancara dengan manajemen PT.PINDAD (Persero) dan perumusan strategi PT.PINDAD (Persero) menggunakan pendekatan QSPM. Hasil penelitian ini PT.PINDAD (Persero) melakukan Inovasi untuk menghadapi tantangan di era Industri 4.0 dan ancaman kejahatan siber. Aspek terbesar yang menjadi kekuatan dan peluang PT.PINDAD (Persero) adalah memiliki relasi dengan pemerintah yang mulai memandang keamanan siber sebagai prioritas pembangunan. Sementara itu, kelemahan dan ancaman yang dihadapi PT.PINDAD (Persero) adalah adanya kendala oleh terbatasnya fasilitas dan keterbatasan sumber daya manusia untuk memulai bisnis siber sekuriti PT.PINDAD (Persero) serta diversifikasi usaha perusahaan pesaing dalam hal IT. Sementara strategi yang menjadi prioritas PT.PINDAD (Persero) adalah strategi yang memfokuskan bisnis yang ditawarkan pada pengembangan sumber daya manusia, proses, dan teknologi dalam bidang keamanan siber dengan bekerjasama dengan KOMINFO menyelenggarakan seminar dan workshop terkait Inpres No.3 Tahun 2003 untuk memasuki pasar pemerintah.
\end{abstract}

Kata Kunci: PT.PINDAD, Cyber Security, Inovasi Industri, Industry 4.0, Industri Persenjataan.

\section{PENDAHULUAN}

Revolusi Industri 4.0 yang pertama kali dikenalkan saat Hannover Fair pada tahun 2011 lalu semakin menunjukkan perkembangan dan kemajuannya beberapa waktu terakhir. Revolusi Industri generasi ke empat ini merupakan fenomena unik yang menjadikan HighTech dan internet sebagai ciri utama perkembangannya. Revolusi Industri 4.0 juga diasumsikan dapat meningkatkan daya saing industri setiap negara untuk menghadapi dunia global yang bergerak sangat dinamis dengan semakin dioptimalkannya penggunaan teknologi dan internet di setiap aspek pergerakan industri saat sekarang ini. Akan tetapi Revolusi Industri 4.0 juga memiliki tantangan tersendiri yang apabila tidak diantisipasi dengan tepat justru akan menjadi ancaman. Salah satu ancaman yang dapat terjadi era Revolusi Industri 4.0 adalah cyber crime. Cyber crime dengan berbagai motif dan levelnya merupakan kejahatan di dunia maya dengan komputer dan jaringan komputer sebagai unsur utamanya yang dapat merugikan berbagai pihak baik itu secara perorangan maupun badan atau instansi.

Contoh kasus cyber crime di Indonesia sudah terjadi berkali-kali baik itu

\footnotetext{
${ }^{1}$ Muhammad Haikal Kautsar, S.E. Mahasiswa Program Pascasarjana Universitas Pertahanan. Program Studi Ekonomi Pertahanan. Cohort 10. email: kautsarhaikal@yahoo.com

${ }^{2}$ Nurina Munasyaroh, S.E. Mahasiswa Program Pascasarjana Universitas Pertahanan. Program Studi Ekonomi Pertahanan. Cohort 10. email: nurinanrn@gmail.com

${ }^{3}$ Putri Alyani Fadhilah, S.E. Mahasiswa Program Pascasarjana Universitas Pertahanan. Program Studi Ekonomi Pertahanan. Cohort 10. email: pealyani@gmail.com

${ }^{4}$ Ikhsan Yoga Utama, S.E. Mahasiswa Program Pascasarjana Universitas Pertahanan. Program Studi Ekonomi Pertahanan.

Cohort 10. email: ikhsanyogut@gmail.com

${ }^{5}$ Supandi. Sekretaris Program Studi Ekonomi Pertahanan Universitas Pertahanan. email: pendisupandi@gmail.com
} 
berupa pemalsuan akun, website hack, pencurian data dan uang. Cyber crime akan semakin berbahaya jika sasaran kejahatan adalah instansi atau perusahaan yang menjaga kerahasiaan datanya dalam sistem kerja perusahaan yang terintegrasi dengan internet untuk kemudian tersimpan dalam sistem database online. Oleh karena itu, dibutuhkan suatu protect system yang diharapkan memberikan perlindungan dan keamanan terutama bagi pengguna yang menggantungkan keberlangsungan sistem kerjanya melalui jaringan internet. Dalam hal ini cyber security adalah aplikasi teknologi yang menjadi suatu kebutuhan yang penting sebagai salah satu cara untuk melindungi pengguna dari ancaman cyber crime.

Saat ini, perkembangan yang pesat dari teknologi sensor, interkoneksi, dan analisis data memunculkan gagasan untuk mengintegrasikan seluruh teknologi tersebut ke dalam berbagai bidang industri (Hoedi, 2017), termasuk industri pertahanan. PT.PINDAD (Persero) sebagai perusahan Badan Usaha Milik Negara (BUMN) yang bergerak di bidang industri pertahanan ternyata sudah berinovasi memulai lini bisnis baru di bidang jasa pelayanan cyber security. Cyber security ini merupakan suatu bentuk inovasi Ambidextrous mengingat core bisnis PT.PINDAD (Persero) sebelumnya bergerak di bidang manufaktur persenjataan fisik.

Lini baru bisnis pelayanan jasa cyber security di PT.PINDAD (Persero) juga didasari atas kesadaran bahwa cyber crime bisa mengancam di berbagai sektor antara lain pelayanan publik, ekonomi, pertahanan, keamanan, dan energi. Pertahanan cyber juga tidak mengenal batas teritorial negara serangan bisa datang dari dalam maupun dari luar (PINDAD, 2018). Tentunya keputusan PT.PINDAD (Persero) untuk menjalankan core bisnis baru yang berbeda dengan core utamanya tidak hanya didasari pada kesadaran akan bahayanya cyber crime, akan tetapi PT.PINDAD (Persero) dinilai dapat melihat peluang strategi yang berpotensi dapat mengembangkan perusahaan dan meningkatkan kinerja organisasi perusahaan. Keputusan
PT.PINDAD (Persero) dalam menambahkan core bisnis yang sama sekali berbeda dengan core bisnis sebelumnya ini yang justru menjadi dasar bagi peneliti untuk menganalisis strategi PT.PINDAD (Persero) dalam lini bisnis barunya, yaitu cyber security dengan menilai aspek-aspek dari Strenght (kekuatan), Weakness (kelemahan), Opportunities (Peluang Bisnis), dan Threats (Hambatan) untuk selanjutnya menyusun strategis prioritas yang diperlukan untuk pengembangan lini bisnis siber sekuriti PT.PINDAD (Persero).

Dari latar belakang yang telah dipaparkan di atas, penelitian dilakukan dengan tujuan untuk menganalisis strategi PT.PINDAD (Persero) dalam pengembangan cyber security sebagai lini bisnis terbarunya.

Rumusan Masalah dari penelitian ini adalah Bagaimanakah Strength (Kekuatan), Weakness (Kelemahan), Opportunities (Peluang Bisnis), dan Threats (Hambatan) yang dihadapi PT.PINDAD (Persero) dalam pengembangan cyber security sebagai lini bisnis terbarunya?

\section{ISI PENELITIAN}

Penelitian ini dilandasi dengan teori Ambidexterity Innovation atau Dual Innovation.

\section{Teori Ambidexterity Innovation}

Dual Innovation atau Ambidexterity Innovation adalah teori yang menjelaskan sebuah langkah dari perusahaan dalam melakukan inovasi di luar bisnis utamanya tetap mampu menjalankan bisnis utamanya baru secara bersama (Duncan, 1976; Tushman dan O'Reilly, 2004; Markides, 2006; Ralph 2017). Perusahaan melakukan bentuk inovasi dengan mengembangkan lini bisnis baru yang diyakini sebagai aspek penting untuk membangun kesuksesan kompetitif (Einsenhardt dan Martin, 2000; Damanpour, 2018; Liu dan Gima, 2018; Lempiala, 2017.). Beberapa penelitian menemukan bahwa pengembangan bisnis baru membutuhkan struktur, process, keterampilan, dan strategi yang sulit

Volume 4 Nomor 1, September 2019 | 2 
dikombinasikan bahkan berkontradiksi dengan yang dimilliki pada bisnis utama (Benner Rushman, 2003; Bedford, 2018; Sheremata, 2000). PT.PINDAD (Persero) adalah perusahaan BUMN yang bisnis utamanya adalah persenjataan dan komponen militer. PT.PINDAD (Persero) memutuskan untuk melakukan inovasi dalam lini bisnisnya dengan memberikan pelayanan keamanan siber. Hal ini merupakan sebuah bentuk inovasi ambidexterous karena PT.PINDAD (Persero) mencoba inovasi produk di sektor yang berbeda dari bisnis utama.

Ketika perusahaan mampu menciptakan keseimbangan antara bisnis utama dan bisnis baru yang dikembangkan maka perusahaan tersebut menjadi perusahaan Ambidexterous. Beberapa penelitian menemukan hubungan positif antara kinerja organisasi dengan kemampuan Amidextrous (Adler, et al, 1999; Ahuja Lampert, 2001; Acosta, 2018;). Strategi perusahaan untuk menciptakan keseimbangan antara bisnis utama dengan bisnis yang baru dikembangkan adalah dengan cara membentuk unit terpisah dari perusahaan induk (Christensen dan Raynor, 2003; O'Reiley dan Tushman, 2004.). Unit baru yang bertanggung jawab untuk pengembangan bisnis baru perlu diberikan kesempatan dalam otonomi karena memiliki lingkungan dan tantangan yang berbeda, sehingga perlu untuk merumuskan strategi, keuangan, dan keputusan operasi (Markides, 2006). PT.PINDAD (Persero) menjadikan pelayanan keamanan siber sebagai salah satu unit bisnis yang dalam inovasinya. Sehingga diperlukan persiapan strategi untuk pengembangan inovasi bisnis PT.PINDAD (Persero). Penelitian ini akan menganalisis strategi yang dilakukan oleh PT.PINDAD (Persero) dalam pengembangan lini bisnis barunya yaitu Keamanan Siber.

\section{Keamanan Siber}

Keamanan siber adalah upaya perlindungan perangkat digital dari ancaman yang hadir dari perkembangan teknologi dan dunia siber (Venkatachary, et al, 2018). Bentuk ancaman yang hadir berupa serangan langsung dari orang yang memiliki niat buruk dan perangkat lunak pengganggu. Hal ini dapat menyebabkan penurunan produksi, reputasi, pendapatan penjualan, dan keselamatan jiwa (Daniel, et al, 2016). Oleh karena itu permintaan terhadap pengamanan siber semakin meningkat di era Industri 4.0. Sehingga PT.PINDAD (Persero) dapat menjadikan ini peluang dengan mempersiapkan strategi untuk merespon permintaaan Pasar.

\section{Manajemen Strategik}

Strategi adalah arah dan ruang lingkup sebuah organisasi dalam jangka waktu tertentu untuk meraih tujuan dari organisasi melalui konfigurasi sumber daya dan kaidah-kaidah tertentu yang sesuai dengan tahapan untuk mencapai tujuan (Johnson dan Shcoles, 2016). Dalam dunia militer strategi sering didefinisikan sebagai formulasi antara ends (sesuatu yang ingin dicapai), means (sumber daya yang dimiliki), dan ways (cara penggunaan sumber daya) (Lykke, 1989).

Strategi dalam perusahaan sering dikaitkan dengan manajemen strategik. Manajemen strategik merupakan seni dan pengetahuan untuk memformulasikan, mengimplementasikan, dan mengevaluasi keputusan lintas fungsional yang membuat organisasi mampu mencapai tujuannya (David, 2009). Dengan implementasi manajemen strategik perusahaan mampu mengidentifikasi ancaman dan peluang yang dapat menghambat atau menjadi katalisator untuk mencapai tujuan. Meskipun pada akhirnya tidak ada definisi tunggal mengenai strategi, karena strategi sangat berkaitan dengan kebijakan, tujuan, taktik, sasaran, dan program, karena setiap definisi mengenai strategi memiliki keterbatasan dan asumsi masing-masing (Mainardes, Ferreira, \& Raposo, 2014). Proses penyusunan perencanaan strategis melalui tiga tahap analisis, yaitu tahap pengumpulan data, tahap analisis, tahap pengambilan keputusan (Rangkuti, 2015).

Salah satu bentuk cara perumusan strategi adalah analisis SWOT, SWOT adalah singkatan dari Strenght (kekuatan), Weakness (kelemahan), Opportunities

Volume 4 Nomor 1, September 2019 | 3 
(Peluang Bisnis), dan Threats (Hambatan). Analisis SWOT adalah analisis yang terdiri dari analisis lingkungan mikro yang bertujuan untuk mengetahui kekuatan dan kelemahan perusahaan, dan analisis lingkungan makro untuk mengetahui peluang dan ancaman bagi perusahaan (Nuary, 2016). Setelah dilakukan Analisis SWOT maka tahap selanjutnya adalah tahap pengambilan keputusan. Pada tahap pengambilan keputusan pendekan QSPM (Quantitative Strategic Planning Method).

\section{QSPM (Quantitative Strategic Planning Method)}

QSPM adalah suatu pendekatan penyusunan perencanaan strategi secara kuantitatif dengan mempertimbangkan faktor-faktor kunci sebagai landasan pengambilan keputusan dari alternatif strategi yang ada (David F. R., 1986). Komponen-komponen dasar dari analisis QSPM adalah: (1) faktor kunci, (2) strategi yang akan dievaluasi, (3) rating, (4) skor attractiveness, (5) total skor attractiveness, (6) Jumlah total skor attractiveness. Faktorfaktor yang biasanya dijadikan faktor kunci adalah faktor internal dan faktor eksternal organisasi. Tujuan penggunaan QSPM adalah untuk menentukan alternatif strategi pengembangan lini bisnis siber sekurity PINDAD. QSPM sebagai alat analisis memiliki kelebihan dan kekurangan, yaitu: (1) strategi dapat diperiksa secara berurutan atau bersamaan; (2) tidak ada batas jumlah strtategi yang dapat diperiksa atau dievaluasi; (3) membutuhkan ketelitian dalam memadukan faktor-faktor eksternal dan internal yang terkait dalam proses keputusan (Ramadhan \& Sofiyah, 2013).

Analisis SWOT dan QSPM pernah dilakukan oleh Hashemi, et al. (2011) melakukan penelitian terhadap perusahaan gelas HAMADAN. Setelah dilakukan analisis SWOT dan QSPM strategi terbaik yang dapat dilakukan oleh perusahaan adalah membangun unit ketiga untuk produksi botol berwarna lebih dahulu dan diprioritaskan dibandung strategi lainnya (Hashemi, Mazdeh, Razeghi, \& Rahimian, 2011). Leiber, et al. (2018) melalukan penelitian pada institusi pendidikan tinggi di eropa dengan melakukan analisis SWOT untuk menemukan jembatan antara teori dan dampak praktis dalam kualitas pendidikan tinggi dan menemukan SWOT analisis dapat digunakan sebagai jembatan untuk mengatasi gap antara tantangan metodologis dengan implementasi dari dampak pengukuran dalam sistem manajemen kualitas. Penelitian lainnya yang dilakukan oleh Wijayanto (2016) mengenai pengembangan perikanan di Biak, menemukan 22 alternatif strategi pengembangan perikanan dari hasil analisis SWOT dan QSPM, sementara strategi yang menjadi prioritas adalah pengembangan pelabuhan nelayan "Wadibu", tempat pencarian ikan "Fadoi" dan "Bosnik" (Wijayanto, 2016).

\section{Metode Penelitian}

Penelitian ini menggunakan metode penelitian kualitatif, yaitu suatu metode penelitian yang berlandaskan pada filsafat postpositivisme yang digunakan untuk meneliti pada kondisi obyek alamiah, di mana peneliti adalah sebagai instrumen kunci, dengan teknik pengumpulan data dilakukan secara gabungan, analisis data yang bersifat induktif/kualitatif, dan hasil penelitian yang lebih menekankan makna dari pada generalisasinya (Sugiyono, 2013). Dalam metode penelitian kualitatif, akan mengarahkan penelitian pada jenis penelitian deskriptif, di mana hal tersebut dapat membuat peneliti mendapatkan informasi secara lengkap dan mendalam mengenai permasalahan yang terjadi dari para informan (Sutandar, 2017).

Narasumber yang dipilih dalam penelitian ini berasal dari internal perusahaan, yaitu manajemen PT.PINDAD (Persero) dengan tujuan untuk mengetahui lebih dalam mengenai strategi pengembangan inovasi produk yang dilakukan oleh PT PINDAD (Persero). Dalam penelitian kualitatif dibutuhkan suatu data. Sugiyono (2013) menjelaskan bahwa dalam penelitian kualitatif dibutuhkan data yang pasti, yaitu data yang sebenarnya sebagaimana adanya, bukan data yang sekedar terlihat, terucap, tetapi data yang mengandung makna balik yang terlihat dan terucap tersebut. Sumber data yang digunakan dalam penelitian ini Volume 4 Nomor 1, September 2019 | 4 
didapatkan melalui dua sumber, yaitu data primer dan data sekunder. Data primer yang ada dalam penelitian ini didapatkan dengan menggunakan metode wawancara mendalam (in-depth interview) dengan narasumber/informan yang akan diwawancarai. Sedangkan untuk data sekunder didapatkan melalui website PT Pindad (Persero).

Pengumpulan data dari penelitian ini didapatkan dengan menggunakan teknik wawancara, di mana teknik yang digunakan yaitu jenis wawancara terbuka atau wawancara tak-terstruktur untuk mendapatkan informasi yang mendalam mengenai kekuatan, kelemahan, peluang, dan ancaman lini bisnis Siber sekuriti PT PINDAD (Persero). Menggunakan metode analisis data deskriptif yang merupakan cara merumuskan dan menafsirkan data yang ada sehingga memberikan gambaran yang jelas mengenai kekuatan, kelemahan, peluang, dan ancaman adanya inovasi produk terbaru dari PT.PINDAD (Persero). Analisis data deskriptif dari penelitian ini dijelaskan menggunakan matriks SWOT dan Matriks QSPM. Analisis SWOT yaitu identifikasi berbagai faktor yang secara sistematis digunakan untuk merumuskan strategi perusahaan, didasarkan pada logika yang dapat memaksimalkan kekuatan (strengths) dan peluang (opportunities) namun secara bersamaan dapat meminimalkan kelemahan (weakness) dan ancaman (threats) (Tamara, 2016).

Analisis SWOT dalam penelitian ini membutuhkan kuesioner riset SWOT dengan penentuan indikator-indikator SWOT yang dibutuhkan. Perhitungan indikator dilakukan melalui perhitungan bobot dan rating. Bobot adalah nilai yang ditentukan berdasarkan tingkat kepentingan atau urgensi penanganan indikator SWOT dengan skala 1 sampai 0 dengan total keseluruhan bobot tidak lebih dari 1 ( 1 = sangat penting, $0=$ tidak penting). Rating adalah analisis kita terhadap seberapa besar pengaruh faktor tersebut terhadap kondisi perusahaan yang bersangkutan. Nilai rating dibagi untuk variable kekuatan dengan nilai indikator dalam skala 1 sampai 4 (semakin tinggi angkanya semakin kuat indikator tersebut).
Kemudian, variabel kelemahan. Dengan nilai indikator 1 sampai 4 (semakin tinggi angkanya semakin menurun tingkat kelemahan indikator tersebut) (Rangkuti, 2015).

QSPM (Quantitative Strategic Planning Matriks) adalah alat yang memungkinkan para penyusun strategi mengevaluasi berbagai strategi alternatif secara objektif, berdasarkan faktor-faktor keberhasilan penting eksternal dan internal yang diidentifikasi sebelumnya. Teknik ini secara objektif stategi mana yang terbaik. QSPM menggunakan analisis input dari tahap 1 dan hasil pencocokan dari analisis tahap 2 untuk secara objektif (Ramadhan \& Sofiyah, 2013).

\section{Hasil dan Pembahasan}

Setelah data dikumpulkan melalui wawancara dengan kepala bidang Produk Keamanan siber PT. PINDAD (Persero). Selanjutnya, peneliti menyusun matriks IFE dan matriks EFE yang digunakan untuk mengetahui seberapa besar peranan dari faktor-faktor internal yang terdapat pada perusahaan. Matriks IFE menggambarkan kondisi internal perusahaan yang terdiri dari kekuatan dan kelemahan yang dihitung berdasarkan rating dan bobot. 


\begin{tabular}{|c|c|c|c|}
\hline FAKTOR INTERNAL & ВОВОт & RATING & SKOR \\
\hline \multicolumn{4}{|c|}{ Kekuatan } \\
\hline $\begin{array}{l}\text { Citra perusahaan sebagai } \\
\text { perusahaan yang bergerak } \\
\text { dalam bidang pertahanan }\end{array}$ & 0,1 & 3 & 0,3 \\
\hline $\begin{array}{c}\text { Sebagai perusahaan } \\
\text { BUMN dapat berperan } \\
\text { sebagai auditor } \\
\text { independen keamanan } \\
\text { siber }\end{array}$ & 0,2 & 4 & 0,8 \\
\hline $\begin{array}{l}\text { Memiliki Relasi dengan } \\
\text { Pemerintah }\end{array}$ & 0,4 & 5 & 2 \\
\hline $\begin{array}{l}\text { Sebagai perusahaan } \\
\text { BUMN yang dimiliki } \\
\text { pemerintah dapat } \\
\text { menjamin kerahasiaan dan } \\
\text { kepentingan pemerintah }\end{array}$ & 0,1 & 4 & 0,4 \\
\hline $\begin{array}{c}\text { Memiliki kepercayaan lebih } \\
\text { untuk menjalin kerjasama } \\
\text { dengan industri pertahanan } \\
\text { negara lain }\end{array}$ & 0,2 & 4 & 0,8 \\
\hline \multicolumn{4}{|c|}{ Kelemahan } \\
\hline $\begin{array}{l}\text { Sebagai pendatang baru } \\
\text { pada dunia siber sekuriti } \\
\text { belum mendapat } \\
\text { kepercayaan dari publik }\end{array}$ & 0,3 & 4 & 1,2 \\
\hline $\begin{array}{l}\text { Keterbatasan sumber daya } \\
\text { manusia untuk memulai } \\
\text { bisnis siber sekuriti }\end{array}$ & 0,2 & 5 & 1 \\
\hline $\begin{array}{l}\text { Terkendala fasilitas untuk } \\
\text { menjalankan usaha }\end{array}$ & 0,1 & 4 & 0,4 \\
\hline $\begin{array}{c}\text { Pemasaran yang belum } \\
\text { masif }\end{array}$ & 0,4 & 4 & 1,6 \\
\hline TOTAL & & & 8,5 \\
\hline
\end{tabular}

Tabel 1. Matriks IFE

Berdasarkan matriks IFE terlihat kekuatan terbesar bisnis siber sekuriti PT.PINDAD (Persero) adalah memiliki relasi dengan pemerintah. Aspek internal ini merupakan keunggulan kompetitif PT.PINDAD (Persero) dalam bisnis siber sekuriti dibanding perusahaan swasta lainnya. Sementara aspek kelemahan PT.PINDAD (Persero) adalah terkendala terbatasnya fasilitas dan keterbatasan sumber daya manusia untuk memulai bisnis siber sekuriti PT.PINDAD (Persero). Selanjutnya setelah disusun matriks IFE maka akan disusun matriks EFE. Matriks EFE memiliki tujuan untuk menganalisis faktor eksternal yang tidak dapat dikendalikan yang berpengaruh terhadap organisasi. Tabel 2 menunjukan matris EFE.

\begin{tabular}{|c|c|c|c|}
\hline FAKTOR EKSTERNAL & Вовот & RATING & SKOR \\
\hline \multicolumn{4}{|c|}{ Peluang } \\
\hline $\begin{array}{lr}\text { Pesaing } & \text { kurang } \\
\text { independen } & \text { dalam } \\
\text { melakukan audit risiko IT }\end{array}$ & 0,2 & 3 & 0,6 \\
\hline $\begin{array}{ll}\text { Pesaing dari perusahaan } \\
\text { swasta belum bisa } \\
\text { menjamin kepentingan } \\
\text { dan } & \text { kerahasiaan } \\
\text { pemerintah } & \end{array}$ & 0,2 & 4 & 0,8 \\
\hline $\begin{array}{l}\text { Pemerintah mulai } \\
\text { memandang keamanan } \\
\text { siber sebagai prioritas } \\
\text { pembangunan }\end{array}$ & 0,3 & 5 & 1,5 \\
\hline 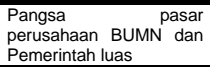 & 0,2 & 3 & 0,6 \\
\hline $\begin{array}{l}\text { Kompetitor swasta belum } \\
\text { banyak }\end{array}$ & 0,1 & 3 & 0,3 \\
\hline \multicolumn{4}{|c|}{ Ancaman } \\
\hline $\begin{array}{lr}\text { Diversifikasi } & \text { usaha } \\
\text { perusahaan } & \text { pesaing } \\
\text { dalam hal IT: system } \\
\text { integrator, } \\
\text { Consulting }\end{array}$ & 0,5 & 4 & 2 \\
\hline $\begin{array}{l}\text { Memiliki pengalaman } \\
\text { lebih dari } 10 \text { tahun }\end{array}$ & 0,3 & 3 & 0,9 \\
\hline $\begin{array}{lrr}\text { Memiliki fasilitas dan } & \text { dan } \\
\text { sumber } & \text { daya yang } \\
\text { mencukupi dan memadai } \\
\text { untuk } & \text { kelangsungan } \\
\text { bisnis } & & \\
\end{array}$ & 0,2 & 5 & 1 \\
\hline TOTAL & 1 & & 7,7 \\
\hline
\end{tabular}

Tabel 2. Matriks EFE

Berdasarkan matriks EFE terlihat bahwa yang menjadi peluang terbesar bagi PT.PINDAD (Persero) adalah Pemerintah mulai memandang keamanan siber sebagai prioritas pembangunan. Peluang ini merupakan momentun bagi PT.PINDAD (Persero) untuk mengisi pasar yang disediakan Pemeritnah dalam pembangunan keamanan siber. Di sisi lain, ancaman terbesar yang dihadapi oleh PT.PINDAD (Persero) adalah diversifikasi usaha perusahaan pesaing dalam hal IT: system integrator, Management Consulting, dsb. Diversifikasi yang ditawarkan oleh pesaing menjadi ancaman ditengah keterbatasan PT.PINDAD (Persero) dan baru masuknya PT.PINDAD (Persero) ke industri keamanan siber.

Setelah dilakukan analisis Internal Factor dan External Factor menggunakan pendekatan SWOT, maka dapat disusun matriks strategi SWOT. Matriks ini merumuskan strategi yang dapat disusun dengan mengacu kepada Kekuatan, Kelemahan, Peluang, dan Ancaman. Setiap kuadran merupakan kombinasi antara komponen internal dan komponen eksternal. Matriks SWOT diperlihatkan pada Tabel 4.3. 


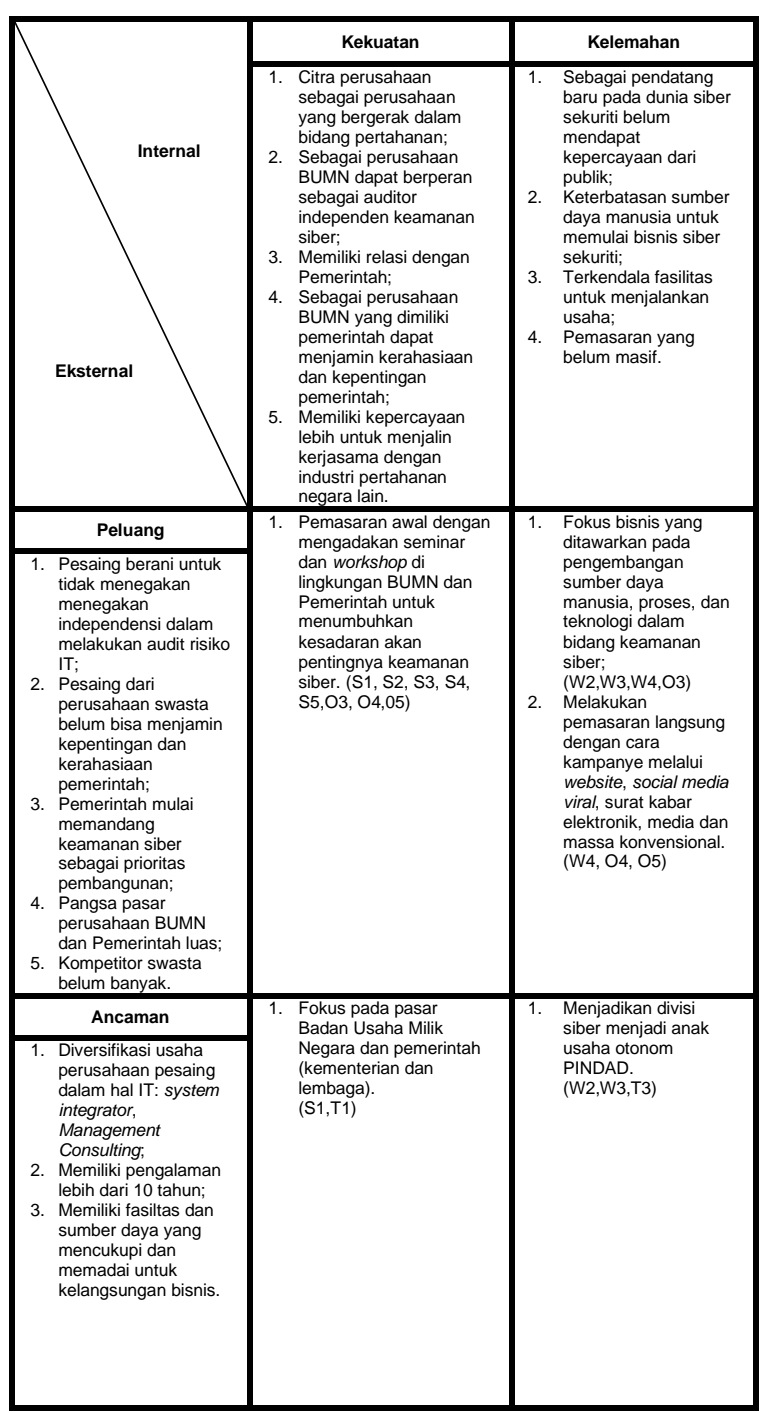

Tabel 3. Matriks SWOT

Berdasarkan matriks SWOT, melalui kombinasi faktor internal dan faktor eksternal, terdapat empat strategi yang dapat dirumuskan untuk pengembangan bisnis siber sekuriti PT.PINDAD (Persero). Empat strategi tersebut yaitu (1) melakukan strategi pemasaran awal dengan mengadakan seminar atau workshop di lingkungan BUMN dan Pemerintah untuk menumbuhkan kesadaran akan pentingnya keamanan siber, (2) fokus bisnis yang ditawarkan pada pengembangan sumber daya manusia, proses, dan teknologi dalam bidang keamanan siber, (3) melakukan pemasaran langsung dengan cara kampanye melalui website, social media viral, surat kabar elektronik, media dan massa konvensional, dan (4) fokus pada pasar Badan Usaha Milik Negara dan pemerintah (kementrian dan lembaga), dan menjadikan divisi siber menjadi anak usaha otonom PT.PINDAD (Persero).

Selanjutnya, untuk menentukan strategi yang menjadi prioritas, strategi yang ada dinilai melalui matriks QSPM. Tingkatan prioritas ditentukan oleh nilai Full Attractive Score (FAS) tertinggi. Full Attractive Score (FAS) diperoleh dari perhitungan perkalian antara bobot dengan Attractive Score. Hasil perhitungan Full Attractive Score (FAS) ditunjukan pada tabel 4.4 .

\begin{tabular}{|c|c|c|c|c|c|c|c|c|c|c|c|}
\hline \multicolumn{10}{|c|}{ Matriks QSPM } \\
\hline Faktor-Faktor & \multicolumn{1}{|c|}{ SO-1 } & \multicolumn{1}{|c|}{ ST-1 } & \multicolumn{2}{|c|}{ WO-1 } & \multicolumn{2}{|c|}{ WO-2 } & \multicolumn{2}{|c|}{ WT-1 } \\
\hline Faktor & Bobot & AS & FAS & AS & FAS & AS & FAS & AS & FAS & AS & FAS \\
\hline St.1 & 0,1 & 4 & 0,4 & 4 & 0,4 & 4 & 0,4 & 4 & 0,4 & 1 & 0,1 \\
\hline St.2 & 0,2 & 3 & 0,6 & 1 & 0,2 & 4 & 0,8 & 4 & 0,8 & 1 & 0,2 \\
\hline St.3 & 0,4 & 4 & 1,6 & 4 & 1,6 & 4 & 1,6 & 4 & 1,6 & 1 & 0,4 \\
\hline St.4 & 0,1 & 2 & 0,2 & 1 & 0,1 & 4 & 0,4 & 4 & 0,4 & 1 & 0,1 \\
\hline St.5 & 0,2 & 2 & 0,4 & 2 & 0,4 & 1 & 0,2 & 1 & 0,2 & 1 & 0,2 \\
\hline Wk.1 & 0,3 & 3 & 0,9 & 4 & 1,2 & 4 & 1,2 & 4 & 1,2 & 4 & 1,2 \\
\hline Wk.2 & 0,2 & 3 & 0,6 & & 0 & 4 & 0,8 & 4 & 0,8 & 4 & 0,8 \\
\hline Wk.3 & 0,1 & 4 & 0,4 & & 0 & 3 & 0,3 & 3 & 0,3 & 4 & 0,4 \\
\hline Wk.4 & 0,4 & 4 & 1,6 & 4 & 1,6 & 3 & 1,2 & 3 & 1,2 & 4 & 1,6 \\
\hline Op.1 1 & 0,2 & 3 & 0,6 & & 0 & 1 & 0,2 & 4 & 0,8 & 1 & 0,2 \\
\hline Op.2 & 0,2 & 2 & 0,4 & & 0 & 1 & 0,2 & 4 & 0,8 & 1 & 0,2 \\
\hline Op.3 & 0,3 & 4 & 1,2 & 4 & 1,2 & 4 & 1,2 & 4 & 1,2 & 2 & 0,6 \\
\hline Op.4 & 0,2 & 4 & 0,8 & 4 & 0,8 & 4 & 0,8 & 4 & 0,8 & 2 & 0,4 \\
\hline Op.5 & 0,1 & 4 & 0,4 & 4 & 0,4 & 4 & 0,4 & 4 & 0,4 & 1 & 0,1 \\
\hline Th.1 1 & 0,5 & 1 & 0,5 & 3 & 1,5 & 2 & 1 & 1 & 0,5 & 2 & 1 \\
\hline Th.2 & 0,3 & & 0 & 3 & 0,9 & 1 & 0,3 & & 0 & 4 & 1,2 \\
\hline Th.3 & 0,2 & & 0 & 1 & 0,2 & 3 & 0,6 & 2 & 0,4 & 2 & 0,4 \\
\hline Total & & & $\mathbf{1 0 , 6}$ & & $\mathbf{1 0 , 5}$ & & $\mathbf{1 1 , 6}$ & & $\mathbf{1 1 , 8}$ & & $\mathbf{9 , 1}$ \\
\hline
\end{tabular}

Berdasarkan tabel matriks QSPM strategi yang memiliki nilai FAS total paling besar adalah strategi yang memfokuskan bisnis yang ditawarkan pada pengembangan sumber daya manusia, proses, dan teknologi dalam bidang keamanan siber. Menurut kepala unit bisnis cyber security PT.PINDAD (Persero), keamanan siber dapat terwujud ketika proses dari pembentukan sistem pengamanan berjalan dengan baik yaitu terdapat sistem deteksi ancaman yang baik, sistem pencegahan yang baik, sistem perespon ancaman yang baik, dan mampu memprediksi potensi ancaman kedepannya. Proses yang baik dapat dibentuk melalui sumber daya manusia yang baik dan berkualitas (people). Sumber daya manusia yang berkualitas yang dibutuhkan adalah individu yang memiliki patriotisme, passion, bakat, dan kompetensi. Selain itu komponen lainnya 
untuk membentuk proses pengamanan yang baik adalah ketersediaan teknologi yang baik. Oleh karena itu fokus strategi pengembangan bisnis cyber security PT.PINDAD (Persero) adalah membangun sumber daya manusia (people), membangun teknologi yang baik (Technology) agar mampu melahirkan sebuah sistem pengamanan yang baik (process). Setiap aspek dari strategi ini People, Technology, Process dapat menjadi produk utama yang ditawarkan oleh PT.PINDAD (Persero).

\section{PENUTUP}

Dari hasil penelitian ini dapat disimpulkan bahwa lini bisnis siber sekuriti PT.PINDAD (Persero) memiliki prospek yang baik ke depannya dengan mempertimbangkan kekuatan dan peluang yang ada. Namun, tantangan yang dihadapi oleh PT.PINDAD (Persero) dari kelemahan internal organisasi dan ancaman dari pesaing harus mampu ditangani. Strategi yang peneliti rumuskan untuk menjadi prioritas dalam pengembangan lini bisnis siber sekuriti adalah strategi yang memfokuskan bisnis yang ditawarkan pada pengembangan sumber daya manusia, proses, dan teknologi dalam bidang keamanan siber.

Penelitian mengenai analisis lini bisnis siber sekuriti PT.PINDAD (Persero) ini memiliki keterbatasan dalam proses pelaksanaanya. Pertama, analisis internal faktor tidak mempertimbangkan aspek keuangan dikarenakan keterbatasan data yang tersedia. Kedua, eksternal faktor dibatasi sangat sempit. Ketiga, pembobotan dan rating berdasarkan satu narasumber saja. Keempat, opsi strategi yang dirumuskan terbatas. Penelitian selanjutnya diharapkan mampu memperdalam penelitian ini menganalisis lebih dalam terkait internal dan eksternal faktor dengan melibatkan faktor-faktor yang lebih banyak. Penggunaan kuisioner untuk menambah input dalam perhitungan bobot, rating, dan attractiveness score. Sehingga dapat merumuskan opsi strategi yang lebih banyak.

\section{UCAPAN TERIMA KASIH}

Peneliti mengucapkan banyak terima kasih atas dukungan dan bantuan dari Universitas Pertahanan, Dosen Pembimbing, dan pihak manajemen divisi siber sekuriti PT.PINDAD (Persero).

\section{DAFTAR PUSTAKA}

Acosta, P. (2018). Information Technology, Knowledge Management, and Environmetal Dynamism as Drivers of Innovation Ambidexterity: a Study in SMEs. Journal of Knowledge Management, 22(4), 824-849.

Adler, G. P., \& Levine, D. (1999). Flexibility vs Efficiency? A Case study model changeovers in the Toyota production system. Organizational Science, 43-68.

Ahuja, G., \& Lampert, C. M. (2001). Enterpreneurship in Large Corporation: A Longitudinal Study of how established firms create breakthrough inventions. Strategic Management Journal, 521-543.

Basuki, R., Fathoni, A., \& Minarsih, M. M. (2018). Pengembangan Kinerja Sumber Daya Manusia di Honda Semarang Center Berdasarkan Analisis SWOT. Journal of Management.

Bedford, D. S., Bisbe, J., \& Sweeney, B. (2018). Performance Measurement System as Generators of Cognitive Conflict in Ambidextrous Firms. Accounting, Organizaion and Society.

Bedford, D. S., Bisbe, J., \& Sweeney, B. (2018). Performance Measurement System as Generators of Cognitive Conflict in Amdextrous Firms. Journal Accounting, Organizations and Society.

Benner, M., \& Tushman, M. (2003). Exploitation, Exploration, and Process Management: The Productivity Dilemma Revisited. Academy of Management Review, 238-256.

Christensen, C., \& Raynor, M. (1997). The Innovator's Solution. Boston: MA: HBS Press.

Volume 4 Nomor 1, September 2019 | 8 
Damanpour, F., Henriquez, F. S., \& Chiu, H. H. (2018). Internal and External Sources and Adoption of Innovations in Organizations. British Journal of Management, 712-730.

Damanpour, F., Sancez-Henriquez, F., \& Chiu, H. H. (2018). Internal and External Sources and The Adoption of Innovations in Organizations. British Journal of Management $V$, 29(4), 712-730.

Daniel Ani, U. P., He, H. M., \& Tiwari, A. (2017). Review of Cybersecurity issues in Industrial Critical Manufacture: Manufacture in Perspective. Journal of Cyber Security Technology.

David, F. R. (1986). The Strategic Planning Matrix - A Quantitative Approach. Long Range Planning Pergamon Journal, 102-107.

David, R. F. (2009). Manajemen Strategi Konsep. Jakarta: Salemba Empat.

Duncan, R. B. (1976). The Ambidextrous Organization : Designing dual Structure for Innovation. The Management of Organization , 167188.

Eisenhardt, K., \& Martin, J. (2000). Dynamic Capabilities: What are they? Strategic Management Journal, 1105-1121.

Hashemi, F. N., Mazdeh, M. M., Razeghi, A., \& Rahimian, A. (2011). Formulating and Choosing Strategies Using SWOT Analysis and QSPM Matrix: A Case Study of Hamadan Glass Company. Proceedings of the 41st International Conference on Computers \& Industrial Engineering (hal. 366-271). Los Angeles: University of Southern California.

Johnson, G., Whittington, R., \& Scholes, K. (2008). Exploring Strategy. Upper Saddle River: Prentice Hall.

Leiber, T., Stensaker, B., \& Harvey, L. C. (2018). Bridging Theory and Practice of Impact Evaluation of Quality Management in Higer Education Institutions: a SWOT Analysis. European Journal of Higher Education.

Lempiala, T., \& Vanharanta, O. (2017). Rethink the Control-Freedom
Paradox in Innovation: Toward a Multifaceted Understanding of Creative Freedom. The Journal of Applied Behavioral Science, 62-87.

Liu, W., \& Gima, K. A. (2018). Enchaning Product Innovation Performance in a Dysfunctional Competitive Environment. Industrial Marketing Management, 7-20.

Lykke, A. F. (1989, May). Defining Military Strategy. Military Review, hal. 2-8.

Mainardes, E. W., Ferreira, J. J., \& Raposo, M. L. (2014). Strategy and Strategic Management Concept: Are They Recognised by Management Students? Business Administration and Management, 43-61.

Markides, C., \& Chu, W. (2006). Innovation through Ambidexterity: How to Achieve the Ambidextrous Organization. London Business School, 1-39.

Nuary, N. S. (2016). Strategi Pemasaran dengan Pendekatan Analisis SWOT pada PT. Super Sukses Motor Banjarmasin. Jurnal_138-3-jieb.

O'Reilly, C. I., \& Tushman, M. (2004). The Ambidextrous Organization . Harvard Business Review, 74-81.

Prasetyo, H., \& Wahyudi, S. (2017). Industri 4.0: Telaah Klasifikasi Aspek dan Perkembangan Riset. Jurnal Teknik Industri UNDIP.

PT. PINDAD. (2018, November 4). PINDAD CYBER SECURITY. Diambil kembali dari PT. PINDAD: https://www.pindad.com/cybersecurity.

Ralph, C. O. (2017, March 27). A Model for Dual Corporate Innovation Management. Diambil kembali dari Dual Innovation: https://dualinnovation.net/a-model-for-dualcorporate-innovation-management/

Ramadhan, A., \& Sofiyah, F. R. (2013). Analisis SWOT Sebagai Landasan Dalam Menentukan Strategi Pemasaran (Studi McDonald's Ring Road). Jurnal Media Informasi Manajemen, 1-10.

Rangkuti, F. (2015). Teknik Membedah Kasus Bisnis Analisis SWOT. Jakarta: Gramedia Pustaka Utama.

Volume 4 Nomor 1, September 2019 | 9 
Sheremata, W. A. (2000). Centrifugal and Centripetal forces in radical new product development under time pressure. Academy of Management Review, 389-408.

Sugiyono. (2013). Metode Penelitian Bisnis (Pendekatan Kuantitatif, Kualitatif, $R \& D)$. Bandung: Alfa Beta.

Sutandar, L. (2017). Analisis Manajemen Strategis pada PT. Semeru Teknik di Surabaya. AGORA.

Tamara, A. (2016). Implementasi Analisis SWOT dalam Strategi Pemasaran
Produk Mandiri Tabungan Bisnis. Jurnal Riset Bisnis dan Manajemen . Venkatachary, S. K., Prasad, J., \& Samikannu, R. (2018). Cybersecurity and Cyber Terrorism - in energy sector a review. Journal of Cyber Security Technology.

Wijayanto, D. (2016). Fisheries Development Strategies of Biak Numfor Regency, Indonesia. 2nd International Symposium on Aquatic Products Processing and Health (hal. 28-38). Elsevier. 